Revue d'histoire de l'Amérique française

सES REVUE D.HISTOIRE DE L'AMÉRIQUE FRANÇAISE

\title{
Documents canadiens (1823-1862) aux Archives secrètes du Vatican
}

\section{François Beaudin}

Volume 21, numéro 2, septembre 1967

URI : https://id.erudit.org/iderudit/302684ar

DOI : https://doi.org/10.7202/302684ar

Aller au sommaire du numéro

Éditeur(s)

Institut d'histoire de l'Amérique française

ISSN

0035-2357 (imprimé)

1492-1383 (numérique)

Découvrir la revue

Citer ce document

Beaudin, F. (1967). Documents canadiens (1823-1862) aux Archives secrètes du Vatican. Revue d'histoire de l'Amérique française, 21(2), 335-339.

https://doi.org/10.7202/302684ar d'utilisation que vous pouvez consulter en ligne.

https://apropos.erudit.org/fr/usagers/politique-dutilisation/ 


\section{INVENTAIRE D'ARCHIVES}

\section{DOCUMENTS CANADIENS (1823-1862) AUX ARCHIVES SECRETES DU VATICAN}

Après la parution, le 8 décembre 1966, d'une note du Préfet des Archives Secrètes du Vatican ${ }^{1}$, Mgr Martino Giusti, annonçant que la date extrême de consultation était reportée au 7 février 1878, fin du Pontificat de Pie IX, je suis entré en communication avec le P. Yvon Beaudoin, o.m.i., pour lui demander d'aller faire une visite aux Archives Secrètes du Vatican et de me souligner ce qui devient accessible, concernant le Canada, dans les nouvelles séries ouvertes aux chercheurs.

A temps perdu, le $\mathrm{P}$. Beaudoin a patiemment fait un relevé des documents contenus, pour les années 1823 à 1862, dans les séries: Lettres latines et Lettres aux Princes (cardinaux et évêques).

Le 24 juin dernier, il me faisait part du fruit de ses recherches dans la lettre qui suit:

J'ai reçu - dans le temps - votre lettre du 23 mars.

Vous m'excuserez si j'ai tardé à vous répondre...

Les Archives du Vatican, très vastes, surtout pour les papiers de Pie IX, qui comprennent les affaires de l'administration des Etats Pontificaux, ne possèdent guère d'inventaire. Pour trouver quelque chose, il faut pratiquement dépouiller les fonds les uns après les autres, feuilleter 1000 papiers pour en trouver un qui touche une question particulière; cette proportion est encore moins forte pour ce qui concerne le Canada alors territoire dépendant de la Propaganda Fide. Il y a donc peu d'espoir de trouver quelque chose, si ce n'est les lettres directement envoyées au Pape, mais celles-ci, lorsqu'elles traitent des problèmes importants, ont été divisées dans les divers bureaux de la Secrétairerie d'Etat et sont demeurées éparses dans divers fonds. Là où l'on pouvait espérer trouver quelque chose, c'est dans les Lettres latines et les Lettres aux Princes

${ }^{1} \mathrm{cf}$. RHAF, XXI, no 1: 63. 
(cardinaux et évêques). Mais il s'agit de lettres d'occasion (anniversaires, vœux, etc.) et donc de peu d'importance... J'ai relevé au sujet du Canada la liste que je vous envoie... Mes recherches se terminent avec l'année 1861-1862, on trouverait donc davantage de 1862 à 1878 ...

Voici donc cette liste mentionnée plus haut: ARCHIVES SECRETES DU VATICAN

I - Epistolae latinae (posizioni e minute)

[Furent examinées les années 1823-1862]

1834 - n. 61 - Mgr Signay à Grégoire XVI, 19 septembre 1833 (?) (Vœux des 300 prêtres et 500,000 chrétiens du Canada).

Minute de la réponse du Pape, 1er novembre 1834.

1846 - n. 107 - Mgr Signay à Pie IX, 7 août 1846 (Vœux).

Minute de la réponse, 5 septembre 1846.

- n. 109 - Mgr Bourget à Pie IX, 28 juillet 1846.

Minute de la réponse, 5 septembre 1846.

1850 - n. 50 - Pape Pie IX à Mgr Norbert Blanchet en Orégon, 19 juin 1850 (Minute).

- n. 51 - Pape Pie IX à Mgr Magloire Blanchet à Walla Walla, 19 juin 1850 (Minute).

- n. 55 - Chanoine de Québec au Pape, pridie nonas junii (3 juin) 1850.

- Minute de la réponse du Pape, 22 juin 1850.

1852 - n. 2 - Mgr Baillargeon au Pape, 11 août 1850.

- Evêques du Canada (Québec, Kingston, Montréal, Bytown, Toronto, Martyropolis) au Pape, 28 août 1851. 
- Minute de la réponse au Pape, 7 janvier 1852.

- n. 95 - Mgr Magloire Blanchet au Pape, 18 mai 1852.

- Minute de la réponse, 4 août 1852 (et réponse à Mgr Kenrick, 19 novembre 1851).

1854 - n. 133 - Evêques du Canada au Pape, 4 juin 1854.

- Minute de la réponse du Pape, 8 novembre 1854 .

1860 - n. 145 - Minute d'une lettre du Pape aux Evêques canadiens, 5 mai 1860.

(1861) - n. 120 - Minute d'une lettre du Pape à Mssgr Norbert et Magloire Blanchet et à Mgr Modeste Demers, 26 juin 1861.

(1862) - n. 59 - Minute d'une lettre du Pape à Eugène Funcken, Edouard Glowoski, prêtres "Missionnaires de la Résurrection de N.S.J.C.” et aux fidèles allemands résidents au Canada, 13 mars 1861 (remerciements pour soutien du Pape).

- n. 65 - Minute de la lettre du Pape à Mgr J. Joseph, évêque de Toronto, 23 mars 1861 (réponse à la lettre du 15 février pour soutien et aide).

- n. 86 - Minute d'une lettre du Pape aux "filiabus Præsidi et sodalibus congregationis Mariæ Dominæ nostrææ", Montréal, Canada, 4 mai 1861.

II - Epistolae ad principes (posizioni e minute)

[Furent examinées les années 1823-1861]

1850 - n. 88 - Evêques de Montréal, Ottawa, Kingston, au Pape, 11 mai 1850 (retour du Pape à Rome).

- Minute de la réponse, 14 juin 1850. 
1856 - n. 136 - Chapitre de la cathédrale de Montréal à Pie IX, 25 mars 1856 (demande d'approbation des statuts).

- Minute de la réponse, au coadjuteur de Montréal et aux chanoines du chapitre, 10 juillet 1856 (statuts soumis à l'examen de la Cong. de la Propagande).

- n. 157 - Mgr Bourget, év. de Montréal, à Pie IX, Paris, 8 mai 1856 (envoi de son ouvrage: "Cæremonialis episcoporum explanationem ex usibus et traditionibus sanctæ romanæ Ecclesiæ confectus" et considérations sur la liturgie romaine).

- Minute de la réponse du Pape, 10 juillet 1856.

1860 - n. 51 - Catholics of St. John's Newfoundland au Pape, 6 janvier 1860.

- Minute de la réponse, 2 février 1860.

- n. 95 - Evêque d'Halifax à Pie IX, 25 janvier 1860 (guerre d'Italie).

- Minute de la réponse, février 1860.

- n. 389 - Clergé de Kingston au Pape, 23 mars 1860 (guerre d'Italie).

- n. 390 - Clergé de Québec au Pape, 4 mars 1860 (guerre d'Italie).

- Minute de la réponse, 14 juin 1860.

- n. 494 - Clergé de Trois-Rivières au Pape, 15 avril 1860 (guerre d'Italie).

- Minute de la réponse, 19 juillet 1860.

- n. 508 - Pape au Clergé de St-Hyacinthe, 31 mai 1860 (guerre d'Italie).

1861 - n. 101 - Evêque de Toronto au Pape, 7 janvier 1861 (en français) (prières pour le Pape; demande de facultés et de l'érection de N.-D. de la Paix, près des chutes Niagara). 
- Minute de la réponse du Pape, 18 mars 1861.

- n. 255 - Mère Hainault Deschamps, sup. gén. des SS. de la Charité de l'Hôpital général de Montréal au Pape, 20 juin 1861 (approbation de leurs constitutions).

- Minute de la réponse du Pape, 22 août 1861 (la question sera examinée).

- n. 300 - Pie IX à "Petro Adolfo, episcopo Sandevicensi in Canada", 30 septembre 1861 (remerciements pour lettres des curés du 30 août 1861 ces lettres manquent).

- n. 355 - Pie IX à Mgr Bourget, 21 novembre 1861 (minute). (La lettre de Mgr Bourget fut renvoyée à Montréal avec, à la suite, le rescrit de la $\mathrm{S}$. Pénitencerie).

Il ressort donc de tout cela que ce sont encore les Archives de la Congrégation de la Propagation de la Foi, à Rome, qui contiennent la majorité des documents qui restent comme témoins des rapports entre les églises diocésaines du Canada et l'évệque de Rome, du moins pour la période ici concernée, soit 1823-1862.

En terminant, remercions le P. Beaudoin de nous avoir signalé ces sources nouvelles et espérons qu'il pourra un jour nous communiquer la suite, soit 1863-1878. 